\title{
QUÃO ISLÂMICO É O ESTADO ISLÂMICO? A GUERRA DO FIM DOS TEMPOS: O ESTADO ISLÂMICO E 0 MUNDO QUE ELE QUER
}

\author{
HOW ISLAMIC IS THE ISLAMIC STATE? \\ THE WAY OF THE STRANGERS: ENCOUNTERS WITH THE \\ ISLAMIC STATE
}

\author{
José Antonio Lima ${ }^{1}$ \\ A Guerra do Fim dos Tempos: O Estado Islâmico e o Mundo Que Ele Quer \\ Graeme Wood \\ Tradução: Laura Teixeira Motta \\ São Paulo: Companhia das Letras, 2017, 408 páginas \\ ISBN:978-85-359-2926-3
}

Entre os diversos livros escritos a respeito do "Estado Islâmico", o grupo que tomou partes da Síria e do Iraque em 2014 e se projetou como a nova ponta-de-lança do movimento jihadista internacional, A Guerra do Fim dos Tempos: O Estado Islâmico e o Mundo que ele quer, de Graeme Wood, é um dos que mais se destaca. Jornalista e professor do Departamento de Ciência Política da Universidade Yale, Wood conseguiu juntar na obra o melhor de seus dois ofícios: uma apuração cuidadosa se mistura a análises profundas a respeito da atuação do grupo para trazer ao leitor um quadro fascinante de um aspecto altamente significativo do jihadismo: o papel da ideologia. Mas não só por isso A Guerra do Fim dos Tempos é relevante. O livro é um dos poucos a ter a coragem de se perguntar a respeito do papel da religião na ideologia jihadista. Em outras palavras, Wood quer saber quão islâmico é o Estado Islâmico.

Lançado em dezembro de 2016, A Guerra... segue o sucesso de um artigo publicado por Wood no site da revista norte-americana The Atlantic em fevereiro de 2015 e que foi capa da edição impressa de março daquele ano. Intitulado What ISIS Really Wants?² (em tradução livre, 0 que o ISIS realmente quer?), o texto traz excertos do que viria a ser o livro e afirma que o "Estado Islâmico é islâmico. Muito islâmico". 0 artigo provocou um intenso debate nos Estados Unidos por, entre outros motivos, atingir em cheio a argumentação do então presidente daquele país, Barack Obama, a respeito do ISIS. Parte da estratégia da Casa Branca naquela administração consistia em tentar deslegitimar o Estado Islâmico ${ }^{1}$ Jornalista e doutorando em Relações Internacionais pela Universidade de São Paulo. ORCID ID: https:// orcid.org/0000-0002-0781-5793. Link para o Currículo Lattes: http://lattes.cnpq.br/4388962761876870. Contato: zeantoniolima@gmail.com.

${ }^{2}$ WOOD, Graeme. What ISIS Really Wants, The Atlantic, mar 2018. Disponível em: https://www.theatlantic. com/magazine/archive/2015/03/what-isis-really-wants/384980/ 
ao argumentar que não se tratava de um Estado nem era islâmico. Isso ficou claro no discurso de Obama no qual anunciou uma ofensiva contra o grupo. ${ }^{3}$

Agora vamos esclarecer duas coisas: o ISIL [acrônimo usado pelo governo dos Estados Unidos] não é islâmico. Nenhuma religião aceita a morte de inocentes. E a grande maioria das vítimas do ISIL tem sido muçulmana. E o ISIL certamente não é um Estado. (...) O ISIL é uma organização terrorista pura e simples. E não tem outra visão senão a matança de todos os que estão em seu caminho.

A argumentação da Casa Branca na época era compreensível. Além de tentar deslegitimar o adversário, Obama buscava enfraquecer o discurso islamofóbico nos Estados Unidos, cuja existência era vista como capaz de alienar as populações muçulmanas, em especial no território norte-americano, e facilitar o recrutamento por parte de jihadistas. Wood afirmava, em contrapartida, que a estratégia da administração Obama era parte de uma "bem-intencionada, mas desonesta, campanha para negar a natureza religiosa medieval do Estado Islâmico". O livro, assim como artigo, é uma tentativa de debelar essa campanha. E Wood, em grande medida, faz isso com maestria, a partir de relatos detalhados das dezenas de conversas que teve com apoiadores do Estado Islâmico ao longo de dois anos e em quatro continentes.

A união de jornalismo e ciência política produz um resultado interessante. Ao apresentar cada um de seus entrevistados principais e, quando possível, seus familiares, Wood, com uma escrita fácil (e ótima tradução para o português de Laura Teixeira Motta) não apenas instiga a leitura como dá elementos para o leitor refletir a respeito de como o recrutamento para a jihad ocorre e quais são as dinâmicas em comunidades muçulmanas no mundo ocidental. 0 alfaiate egípcio Hesham Elashry, que Wood conheceu na praça Tahrir, no centro do Cairo, capital do Egito, nos protestos da Primavera Árabe contra Hosni Mubarak, tenta convertê-lo ao islã a todo custo e, sem sucesso, o manda para Alexandria, onde acreditava que outros irmãos de fé teriam mais sucesso. 0 australiano Musa Cerantonio descreve como ele e outros colegas simpáticos ao Estado Islâmico paulatinamente se afastaram do mainstream muçulmano australiano até passarem a se reunir e orar fora das mesquitas, onde podiam discutir com mais tranquilidade suas ideias extremistas.

Ao longo do livro, Wood debate questões importantes, como a história do ISIS e a atuação de seu criador, o jordaniano Abu Musab al-Zarqawi, ainda como um braço da rede terrorista Al-Qaeda, e discute as teses teológicas de seus personagens. Nesta empreitada, o autor não se furta a abordar uma questão sensível, as ligações teológicas e ideológicas entre o Estado Islâmico e a Arábia Saudita. No capítulo 2 da obra, Wood destaca o papel do pensamento de Taqi al-Din ibn Taymiyya (1263-1328), um teólogo que teve atuação destacada em um período de crise para o mundo muçulmano, iniciado em 1258 com o fim

${ }^{3}$ SCHWARTZ, Ian. Obama: “ISIL Is Not Islamic”. Real Clear Politics, 14 set. 2014. Disponível em: https://www. realclearpolitics.com/video/2014/09/10/obama_isil_is_not_islamic.html 
do Califado Abássida, baseado no que hoje é o Iraque, após a conquista dos mongóis. Ibn Taymiyya descrevia o período em que vivia como semelhante ao encontrado por Maomé após a revelação: um ambiente de ignorância, a jahiliyya. Diante disso, pregava um retorno às origens do islã e defendia que seus companheiros de fé seguissem os atos dos primeiros contemporâneos do profeta - al-salaf al-salih ("antepassados veneráveis"). Ibn Taymiyya, assim, é uma espécie de "fundador" do salafismo, vertente do islã no qual o Estado Islâmico e a Arábia Saudita podem ser inseridos.

Wood também salienta a atuação do clérigo Muhammed bin Abd Al-Wahhab (17031792), um reformista salafista pré-moderno que deu origem ao wahabismo, a grosso modo a versão saudita do salafismo. Al-Wahhab articulou de forma intensa o conceito da excomunhão (takfir) de "infiéis", essencial para o Estado Islâmico, e teve papel político determinante. Em 1744, o então líder tribal Muhammad ibn Saud e Al-Wahhab firmaram um acordo que lançou as bases expansionistas para a criação de um Estado religioso na Península Arábica. Tal projeto só foi consolidado em 1932, com a fundação da Arábia Saudita atual. Wood lembra que tanto o ISIS quanto a monarquia Saud se dizem herdeiros de Ibn Taymiyya e Al-Wahhab, mas que ao surgir como um Estado moderno a Arábia Saudita acabou por fazer uma série de acomodações pragmáticas para lidar com o mundo moderno, como acabar com a escravidão e conviver com "infiéis", contrariando inclusive oposições ferrenhas em seu território. 0 Estado Islâmico, lembra o autor, "propõe voltar ao ponto em que a história se bifurcou e seguir pelo outro caminho. A entidade aspira ser uma Arábia Saudita religiosamente mais incisiva, sob uma direção menos indulgente" (WOOD, 2017, pp. 125).

0 capítulo 6 é um dos mais interessantes. Nele, Wood relata seus encontros com Hamza Yusuf e Yasir Qadhi, dois destacados eruditos muçulmanos norte-americanos. Ambos têm posições acadêmicas de destaque. 0 primeiro é fundador do Zaytuna College, instituição muçulmana de ensino na Califórnia, e o segundo é professor do departamento de Estudos Religiosos do Rhodes College, no Tennessee. Os dois são ideologicamente rivais - Yusuf é sufista e Qadhi, salafista - mas, no entendimento de Wood, são incapazes de contrapor o Estado Islâmico quando se trata da argumentação religiosa do grupo. Para o autor, nem essas duas autoridades conseguem demonstrar que o ISIS está teologicamente errado ao defender ideias como a escravidão e o extermínio de "infiéis". Assim, diz Wood, "por mais penoso que seja admitir, muitas afirmações do Estado Islâmico estão dentro das fronteiras do debate racional, ainda que não respeitável" (WOOD, 2017, pp. 310).

A principal crítica que se pode fazer ao livro de Wood é da mesma natureza das sofridas quando da publicação do artigo. A obsessão de provar que o Estado Islâmico é islâmico e de salientar que muitos líderes religiosos se calam ou se negam a debater com o ISIS é tão grande que, por vezes, a argumentação para comprovar a tese central resvala em uma legitimação desta entidade, como no trecho abaixo.

Seé "legítimo" ou não, essa é uma questão que os demais crentes respondem por si mesmos, a imensa maioria com uma negativa. No entanto, essas 
questões de legitimidade são das esferas de opinião e dogma: o fato de a maioria acreditar que o Estado Islâmico é desviante não torna a entidade objetivamente desviante (...). Ser minoria não é sinônimo de ser ilegítimo. Ser minoria significa ser minoria". (WOOD, 2017, pp. 280)

Wood erra ao minimizar a importância do debate a respeito da legitimidade do ISIS pois, como o próprio autor reconhece - não apenas nesta passagem supracitada, mas em algumas outras no livro - o Estado Islâmico é rejeitado pela ampla maioria dos muçulmanos. Tal rejeição é um fato extremamente importante pois a ideologia/teologia do ISIS é moldada justamente para apelar às queixas e aos rancores das populações muçulmanas. Como notou o pesquisador Shadi Hamid, do instituto Brookings, em crítica aceita por Wood após a publicação de seu artigo inicial, a ideologia está profundamente enraizada em fatos sociais e políticos e ignorar esses fatos é pelo menos tão perigoso quanto ignorar a ideologia ${ }^{4}$. No caso do islã e do Oriente Médio, as interações entre religião, política e história são tão embrenhadas que é praticamente impossível separar as três coisas.

$\mathrm{Na}$ história recente, o Oriente Médio é uma região dominada por potências estrangeiras e por elites locais que, não raro, são prepostos daquelas. A luta contra o arbítrio externo e interno teve ao longo do tempo diversas formas, a mais famosa delas provavelmente o pan-arabismo. Ao longo do século 20, no entanto, galvanizou-se como uma das mais atrativas formas de resistência, ou talvez, a mais atrativa, o islã político, um tipo de pensamento segundo o qual "a religião é um sistema que poderia resolver qualquer problema político, econômico ou social criado pela modernização” (ROY, 2012) e que deriva de uma revolução cultural ocorrida nos anos 1960, inicialmente tendo como alvo justamente o nacionalismo árabe (KEPEL, 2006). A matriz ideológica deste fenômeno está na Irmandade Muçulmana, um movimento político-religioso-social fundado no Egito nos anos 1920 que era marcadamente anti-imperialista, anti-ocidental e pregava um retorno à religião (a islamização) para retomar a grandeza perdida pelos povos árabes-muçulmanos vis-à-vis o Ocidente. Não à toa, até hoje maiorias significativas no Oriente Médio defendem a adoção da sharia, a aplicação de punições hudud, como apedrejar adúlteras e decepar a mão de ladrões, assim como a criação de um Estado islâmico ${ }^{5}$ (não necessariamente deste que existiu na Síria e no Iraque e que é largamente rejeitado ${ }^{6}$ ).

Ao longo do tempo, o islã político passou por metamorfoses e, por meio de interações com outras leituras políticas da religião, como o salafismo, produziu um espectro ideológico vasto e complexo. Os elementos mais moderados desta ideologia são partidos

\footnotetext{
${ }^{4}$ WOOD, Graeme. 'What ISIS Really Wants': The Response. The Atlantic, 24 fev 2018. Disponível em: https://www.theatlantic.com/international/archive/2015/02/what-isis-really-wants-reader-responseatlantic/385710/

${ }^{5}$ The World's Muslims: Religion, Politics and Society. Pew Research Center, 30 abr 2013. Disponível em: http://www.pewforum.org/2013/04/30/the-worlds-muslims-religion-politics-society-overview/

${ }^{6}$ LIPKA, Michael. Muslims and Islam: Key findings in the U.S. and around the world. Factank, 9 ago 2017. Disponível em: http://www.pewresearch.org/fact-tank/2017/08/09/muslims-and-islam-key-findings-inthe-u-s-and-around-the-world/
} 
que participam de processos eleitorais, como o AKP da Turquia e a própria Irmandade Muçulmana do Egito. Ainda mais à direita estão os salafistas, que em geral rejeitam o engajamento político-partidário. No ponto mais extremo do salafismo, também fora da política, por óbvio, estão os jihadistas, como o Estado Islâmico. Todas essas vertentes, assim, de alguma forma, estão competindo pelo mesmo público-alvo ${ }^{7}$.

Ao mesmo tempo em que a religião é um elemento a aglutinar as oposições no Oriente Médio, ela serve como ferramenta de legitimação dos governantes locais, a maior parte deles autoritários. Um exemplo relevante é o de Saddam Hussein e da chamada "Campanha da Fé" realizada por seu regime nos anos 1990. Com a derrocada do pan-arabismo, Saddam Hussein, que tirava daí sua legitimidade, foi buscar apoio nos religiosos para se manter no poder sem precisar democratizar o país. Instituiu mutilações e decapitações como sentença de crimes e passou a reprimir o consumo de álcool. Mas não só no Iraque e nem apenas no passado recente o islã foi manipulado. Para ficar em um só exemplo: atualmente, o ditador do Egito, Abdel Fattah al-Sissi, persegue a comunidade LGBT abrindo processos e promovendo prisões com base no "desprezo à religião" e em violações da "moralidade pública". 0 resultado deste tipo de manipulação é uma radicalização ainda maior da religião por meio do fortalecimento dos setores mais extremistas da sociedade. Diante do jihadismo e, mais especificamente, do Estado Islâmico, seria ótimo que as sociedades muçulmanas discutissem a relação do islã com a violência, com a democracia e o Estado contemporâneo, bem como conceitos como sharia e jihad. Ocorre que não há debate aberto sobre quase nada nas ditaduras do Oriente Médio, menos ainda sobre um assunto com potencial para deslegitimar vários dos governos da região.

No caso do ISIS, objeto de estudo de Wood em seu livro, as interações entre ideologia/ teologia, política e história são também óbvias. O grupo se origina no Iraque, onde um importante braço da rede terrorista Al-Qaeda se instalou no vácuo de poder produzido pela invasão liderada pelos Estados Unidos. Derrotada, tal facção ressuscita graças à alienação da população sunita iraquiana por parte do governo xiita local e da guerra civil na Síria. A ideologia religiosa é o óleo que lubrifica as engrenagens das intervenções externas no cenário sírio, das violações de direitos humanos e da total falta de perspectiva de futuro. Essa máquina só funciona, no entanto, em meio ao caos, uma realidade que Wood reconhece no posfácio de seu livro ao escrever que "onde quer que exista injustiça, a selvageria pode ser semeada. Onde quer que exista selvageria, ela pode ser usada e explorada. Onde ela puder ser explorada, o pesadelo pode perdurar" (WOOD, 2017, pp. 351).

Trata-se de uma realidade complexa, que exige análises sofisticadas para ser compreendida. A Guerra do Fim dos Tempos: O Estado Islâmico e o Mundo que ele quer é um livro excelente, bem apurado e bem escrito, que traz um importante aspecto para a reflexão daqueles interessados no Estado Islâmico. Não é, no entanto, uma leitura definitiva, mas parte de um conjunto de muitas obras responsáveis por ajudar a entender alguns dos mais terríveis fatos da atualidade.

${ }^{7}$ WORTH. Robert F. The Pillars of Arab Despotism. The New York review of Books, 9 out. 2014. Disponível em: http://www.nybooks.com/articles/2014/10/09/pillars-arab-despotism/ 
resenha de livro

\section{Referências Bibliográficas:}

KEPEL, G. Jihad: The Trail of Political Islam. Tradução de Anthony F. Roberts. London: I.B. Tauris \& Co Ltda, 2006.

ROY, Olivier. Islam: The Democracy Dilemma. In: WRIGHT, R (editora). The Islamists are Coming - Who they really are / Robin Wright. - Washington, D.C.: Woodrow Wilson Center Press, 2012

WOOD, Graeme. A Guerra do Fim dos Tempos: O Estado Islâmico e o Mundo que ele quer. Tradução de Laura Ferreira Motta. São Paulo: Companhia das Letras, 2017

Texto recebido em: 30 de Maio de 2018 Aprovado para publicação em: 18 de Junho de 2018 